\title{
Structure of Water-insoluble Glucan Synthesized by $\beta$-Transglycosylase of Trichoderma longibrachiatum
}

\author{
Toshio Tanaka and Susumu OI \\ Department of Biology, Faculty of Science, Osaka City \\ University, Osaka 558, Japan
}

Received February 8, 1984

\begin{abstract}
A water-insoluble glucan was synthesized by the $\beta$-transglycosylase of Trichoderma longibrachiatum in a reasonable yield from $1 \%$ cellopentaose as the substrate after $48 \mathrm{hr}$ incubation. The glucan could be completely solubilized by cellulase to give glucose, cellobiose and cellotriose, although the reaction time was about 9 times longer than that required for the complete solubilization of the higher cellodextrin ( $\overline{\mathrm{DP}} 14)$ synthesized by the $\beta$-transglucosylase of Sclerotinia libertiana. The glucan was separated into two main fractions according to the solubility in $\mathrm{NaOH}$ solution, the major soluble in $4 \mathrm{~N}-\mathrm{NaOH}$ and the minor insoluble in it. The structure of the major fraction was investigated by methylation analysis, and it was clearly shown to be a linear $\beta$-1,4glucan having an average degree of polymerization of 19 . These results indicated that the $\beta$ transglycosylase of Trichoderma longibrachiatum had a strict specificity of forming $\beta$-1,4-glucosidic linkages and also had a capacity to elongate the linkage to a higher extent.
\end{abstract}

Typical disproportionating enzymes $(\alpha-$ transglycosylase) such as amylomaltase ${ }^{1)}$ of $E$. coli and D-enzyme ${ }^{2,3)}$ are known to synthesize amylose from lower maltooligosaccharides as the substrate by transferring glucosyl, maltosyl, and maltotriosyl moieties and so on. On the other hand, the $\beta$-transglucosylase of Sclerotinia libertiana was shown to synthesize a higher cellodextrin of $\overline{\mathrm{DP}} 14$ using cellotetraose as the substrate by transferring a glucosyl moiety. ${ }^{4,5)}$ Since the fact indicated a capacity of the enzyme to elongate $\beta$-1,4glucosidic linkages specifically to a higher extent, the transfer action of the enzyme was regarded as a kind of disproportionating reaction on lower cellooligosaccharides. As described above, a disproportionating enzyme action should result in the production of a high molecular weight component, which has the same glucosidic linkage as its substrate, with accompanying production of lower oligosaccharides.

Recently, a $\beta$-transglycosylase was purified to a homogeneous state by several chromatographic procedures from a wheat bran Koji culture of Trichoderma longibrachiatum. ${ }^{6}$ The enzyme could transfer cellobiosyl and cellotriosyl moieties as well as glucosyl moieties from cellopentaose to the acceptor molecule such as cellopentaose upwards with the efficiency of almost $\left.100 \%{ }^{6}{ }^{6}\right)$ As a result of the transfer action it could synthesize a waterinsoluble glucan using cellopentaose as a starting substrate. Therefore, the transfer action of the enzyme was attributed to a disproportionating reaction on $\beta$-1,4-glucosidic linkages. In the present study, we investigted the chemical structure of a high molecular weight component (a water-insoluble glucan) synthesized by the $\beta$-transglycosylase of Trichoderma longibrachiatum, and compared both specificity and capacity of $\beta$-1,4-glucosidic linkage elongation by the enzyme with that of the $\beta$ transglucosylase of Sclerotinia libertiana.

\section{MATERIALS AND METHODS}

Enzymes. $\quad \beta$-Transglycosylase: The enzyme (277.1 units/mg protein) was purified from a wheat bran Koji culture of Trichoderma longibrachiatum as previously reported. ${ }^{6)}$ The specific activity was defined as the amount of enzyme which produced a water-insoluble glucan showing 
turbidity (optical density) of 1.0 at $660 \mathrm{~nm}$ per $\mathrm{ml}$ of the reaction mixture in a $24-\mathrm{hr}$ reaction per $\mathrm{mg}$ of the enzyme protein. Cellulase: A commercial cellulase "Cellulase Onozuka R-10" was purchased from the Kinki Yakult Mfg. Co., and was used to analyze the chemical structures of water-insoluble glucans. The enzyme activity was assayed as described below. A mixture containing $0.8 \mathrm{ml}$ of $0.125 \%$ carboxymethylcellulose (CMC) in $0.02 \mathrm{M}$ acetate buffer, $\mathrm{pH} 6.0$, and $0.2 \mathrm{ml}$ of the enzyme solution was incubated for $120 \mathrm{~min}$ at $40^{\circ} \mathrm{C}$, and the reducing sugars produced were determined by the Nelson-Somogyi method. ${ }^{7)}$ Cellulase activity was referred to as 1 unit when reducing sugar equivalent to $1 \mu \mathrm{mol}$ of D-glucose was produced in 1 min under the given conditions.

Substrates. Cellopentaose was prepared according to the method described in our previous paper. ${ }^{6)}$ Carboxymethylcellulose sodium salt (CMC) was purchased from Wako Pure Chemical Industries Ltd. The higher cellodextrin ( $\overline{\mathrm{DP}} 14)$ was prepared by the enzyme reaction of $\beta$-transglucosylase of Sclerotinia libertiana using cellotetraose as the substrate as described in our previous paper. ${ }^{4)}$

Methylation analysis. Sample $(5 \mathrm{mg})$ was methylated by the method of Hakomori. ${ }^{8)}$ In the methylation repeated three times, the reaction mixture was extracted with chloroform and washed several times with distilled water. After removing chloroform in vacuo, the residue finally obtained was methanolyzed in a sealed tube for $6 \mathrm{hr}$ at $110^{\circ} \mathrm{C}$ with $1.0 \mathrm{ml}$ of $2.2 \mathrm{~N}$ methanolic hydrogen chloride. Methanolysis products were further refluxed in $1.0 \mathrm{ml}$ of $2.0 \mathrm{~N} \mathrm{H}_{2} \mathrm{SO}_{4}$ for $4 \mathrm{hr}$ after removing $\mathrm{HCl}$ by repeated evaporation with methanol. The hydrolysate was neutralized by the addition of $\mathrm{BaCO}_{3}$. After filtration, the filtrate was evaporated to dryness under reduced pressure, and the syrup which remained was reduced and acetylated according to the method previously described. ${ }^{9)}$ Authentic samples of 2,3,4,6-tetra- $O$-methyl-D-glucitol acetate and 2,3,6-tri- $O$-methyl-D-glucitol acetate were also prepared from cellobiose as described above.

Chromatography. GLC was performed using a Shimadzu GC-6ATF gas chromatograph equipped with a column of ECNSS-M on Gaschrom Q $(0.3 \times 200 \mathrm{~cm})$ at $180^{\circ} \mathrm{C}$ for alditol acetates. TLC was performed using silica gel 60 (Merck) and the following mixture: 1-butanol, pyridine, water $(6: 4: 3)$ as the solvent for $4 \mathrm{hr}$, and sugars were detected by a quick dip of the plate into ethanol containing $10 \%$ of sulfuric acid, followed by heating for $10 \mathrm{~min}$ at $120^{\circ} \mathrm{C}$.

\section{RESULTS}

\section{Synthesis of a water-insoluble glucan}

The reaction mixture containing $3.6 \mathrm{ml}$ of $\beta$ -

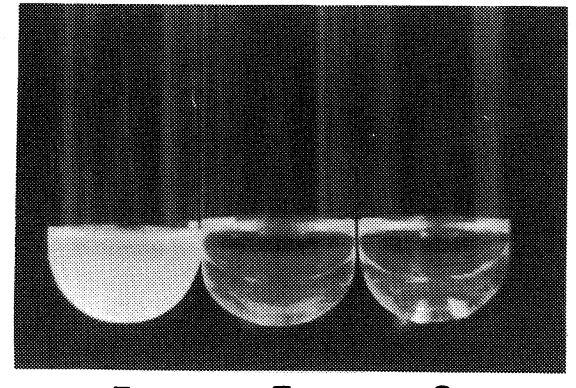

T

$E$

$\mathrm{S}$

FIG. 1. Photograph of the Water-insoluble Glucan Synthesized in the Mixture Containing Cellopentaose and $\beta$-Transglycosylase.

The reaction mixture (T) containing $3.6 \mathrm{ml}$ of $\beta$-transglycosylase (3.5 units $/ \mathrm{ml}$ ) in $0.02 \mathrm{M}$ phosphate buffer, $\mathrm{pH} 6.0$, and $3.6 \mathrm{ml}$ of $2 \%$ cellopentaose was incubated for $48 \mathrm{hr}$ at $30^{\circ} \mathrm{C}$ after adding a few drops of toluene. (E), incubated without the substrate; (S), incubated without the enzyme.

transglycosylase $(3.5$ units $/ \mathrm{ml})$ in $0.02 \mathrm{M}$ phosphate buffer, pH 6.0 and $3.6 \mathrm{ml}$ of $2 \%$ cellopentaose was incubated for $48 \mathrm{hr}$ after adding a few drops of toluene to protect from microbial infection. The enzyme apparently synthesized a water-insoluble glucan under the conditions described above, as shown in Fig. 1. The precipitate was centrifuged and washed several times with distilled water. The recovery yield of the precipitate, which was further washed with acetone and dried overnight at $60^{\circ} \mathrm{C}$, was about $20 \%$ of the cellopentaose initially added. The precipitate was designated as a water-insoluble glucan and employed in the study of the chemical structure.

\section{Enzymic hydrolysis of the water-insoluble glucan}

The susceptibility of the glucan to cellulase action was examined. A reaction mixture containing $0.1 \mathrm{ml}$ of cellulase $(0.12$ units $/ \mathrm{ml})$ in $0.02 \mathrm{M}$ acetate buffer, $\mathrm{pH} 6.0$ and $0.2 \mathrm{ml}$ of the glucan suspension $(20 \mathrm{mg} / \mathrm{ml})$ in distilled water was incubated at $37^{\circ} \mathrm{C}$. At several times, $5 \mu \mathrm{l}$ portions were withdrawn and analyzed by TLC. As shown in Fig. 2, the glucan remaining at the origin of the chromatogram was hydrolyzed by the cellulase action to give glucose, cellobiose, and cellotriose. After $9 \mathrm{hr}$ of 
incubation the glucan was completely solubilized, and the spot at the origin of the chromatogram disappeared. It was apparent that the glucan was mainly composed of $\beta-1,4-$ glucosidic linkages. However, the higher cellodextrin ( $\overline{\mathrm{DP}} 14)$, which was synthesized by $\beta$ transglucosylase of Sclerotinia libertiana, was completely solubilized within $1 \mathrm{hr}$ of incubation under the same conditions. The waterinsoluble glucan seemed to have bigger molecules than the higher cellodextrin ( $\overline{\mathrm{DP}} 14)$.

The course of hydrolysis of the waterinsoluble glucan by cellulase was also examined. The reaction mixture $(1 \mathrm{ml})$ containing the cellulase $(0.06$ units $/ \mathrm{ml})$ in $0.5 \mathrm{ml}$ of $0.02 \mathrm{M}$ acetate buffer, $\mathrm{pH} 6.0$, and $0.5 \mathrm{ml}$ of the higher cellodextrin ( $\overline{\mathrm{DP}} 14)$ suspension $(4 \mathrm{mg} / \mathrm{ml})$ or $0.5 \mathrm{ml}$ of the water-insoluble glucan suspension $(4 \mathrm{mg} / \mathrm{ml})$ in distilled water was incubated at $37^{\circ} \mathrm{C}$. At several times, $0.1 \mathrm{ml}$ portions were withdrawn and reducing sugars were determined. As shown in Fig. 3, the higher cellodextrin ( $\overline{\mathrm{DP}} 14)$ was rapidly hydrolyzed by the cellulase, and the hydrolysis reached a plateau value $(40 \%)$ after about $1 \mathrm{hr}$ incubation. On the other hand, the water-insoluble glucan was hydrolyzed by the cellulase at a lower rate than that of the higher cellodextrin ( $\overline{\mathrm{DP}} 14)$. Also, the rate of hydrolysis significantly decreased after $1 \mathrm{hr}$ of incubation, suggesting the presence of different molecular weight components in the susceptibility to the cellulase action.

Solubility of the water-insoluble glucan in $\mathrm{NaOH}$ solution

It was probable that the $\beta$-transglycosylase of Trichoderma longibrachiatum synthesized a glucan of higher molecular weight than the higher cellodextrin ( $\overline{\mathrm{DP}} 14)$. Therefore, the glucan was examined for solubility in $\mathrm{NaOH}$ solution to estimate the molecular size. Two mg of the water-insoluble glucan or the higher cellodextrin ( $\overline{\mathrm{DP}} 14)$ was suspended in $0.2 \mathrm{ml}$ of distilled water, and mixed with $\mathrm{NaOH}$ solution $(0.1 \mathrm{ml})$ of various concentrations. After the mixture was kept for $5 \mathrm{~min}$ at room temperature, the turbidity was determined at

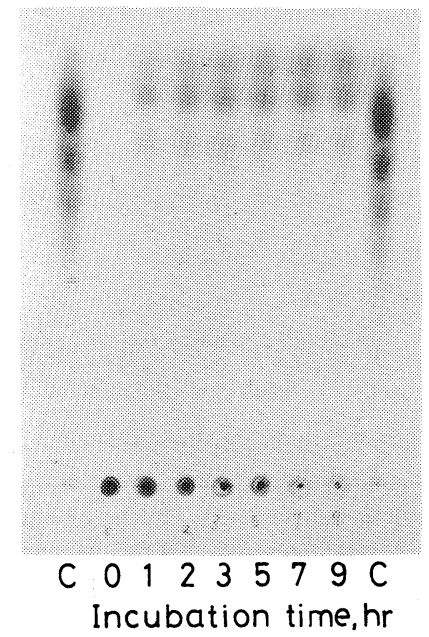

FIG. 2. Thin-layer Chromatogram of Oligosaccharides Produced by Cellulase Action on Water-insoluble Glucan. Markers: C, cellooligosaccharides (glucose $\sim$ cellopentaose) from the top to the bottom of the plate. See the text for details.

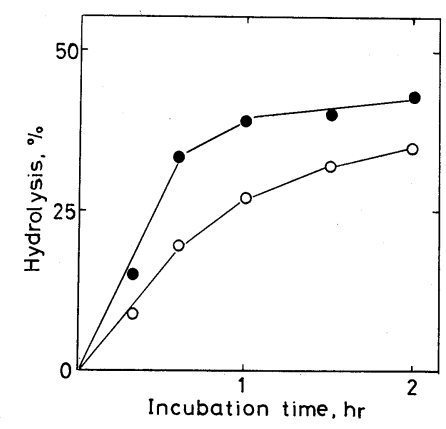

FIG. 3. Course of Hydrolysis of a Water-insoluble Glucan by Cellulase.

, higher cellodextrin; $\bigcirc$, water-insoluble glucan. See the text for details.

$660 \mathrm{~nm}$ using cells of 1-cm pass length. As shown in Fig. 4, the higher cellodextrin ( $\overline{\mathrm{DP}}$ 14) completely dissolved in $1.0 \mathrm{~N} \mathrm{NaOH}$, while the water-insoluble glucan suspension still remained turbid in $4 \mathrm{~N} \mathrm{NaOH}$. The waterinsoluble glucan $(58.7 \mathrm{mg})$ was then dissolved in $3 \mathrm{ml}$ of $4 \mathrm{~N} \mathrm{NaOH}$, and the insoluble moiety was separated by centrifugation. The precipitate was dried overnight at $60^{\circ} \mathrm{C}$ after washing twice with $4 \mathrm{~N} \mathrm{NaOH}$ and several times with distilled water. The dried preparation $(2.5 \mathrm{mg})$ was obtained by the procedures de- 


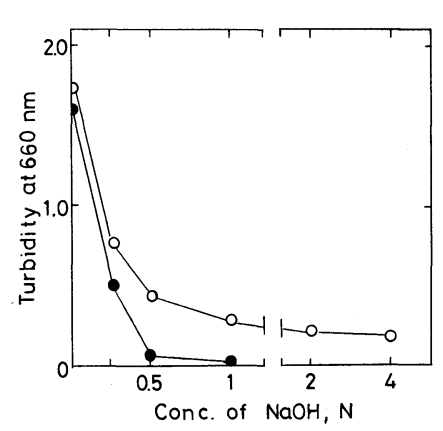

FIG. 4. Solubility of Water-insoluble Glucan in $\mathrm{NaOH}$. The higher cellodextrin $(2 \mathrm{mg})$ or the water-insoluble glucan $(2 \mathrm{mg})$ suspension in $0.2 \mathrm{ml}$ of distilled water was mixed with $\mathrm{NaOH}$ solution $(0.1 \mathrm{ml})$ of various concentrations. The turbidity of each mixture was determined at $660 \mathrm{~nm}$ using cells of $1-\mathrm{cm}$ path length.

o, higher cellodextrin; $\bigcirc$, water-insoluble glucan.

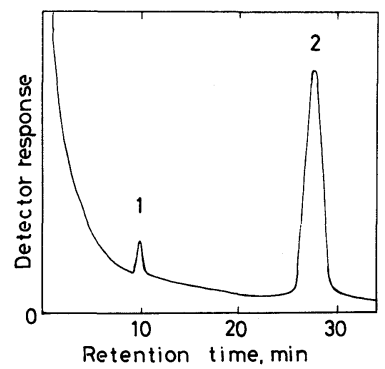

FIG. 5. Gas-liquid Chromatogram of Alditol Acetates Obtained from $4 \mathrm{~N} \mathrm{NaOH}$-soluble Fraction of Waterinsoluble Glucan.

1: 2,3,4,6-tetra- $O$-methyl-D-glucose; 2: 2,3,6-tri- $O$-methylD-glucose. Conditions: the column $(0.3 \times 200 \mathrm{~cm})$ was packed with $3 \%$ ECNSS-M on Gaschrom Q; $180^{\circ} \mathrm{C}$; carrier gas, $\mathrm{N}_{2}(90 \mathrm{ml} / \mathrm{min})$.

scribed above. After removing the $4 \mathrm{~N} \mathrm{NaOH}-$ insoluble precipitate, the $4 \mathrm{~N} \mathrm{NaOH}$-soluble fraction was precipitated again by neutralizing the supernatant with $1 \mathrm{~N} \mathrm{HCl}$. The precipitate $(50.3 \mathrm{mg})$ was also isolated as a dried sample after washing several times with distilled water.

\section{Methylation analysis of the $4 \mathrm{~N} \mathrm{NaOH}$-soluble glucan}

Figure 5 shows the gas-liquid chromatogram of glucitol acetates obtained from the methylated sample of the $4 \mathrm{~N} \mathrm{NaOH}$-soluble glucan. Methyl 2,3,6-tri- $O$-methyl-D-glucose was detected as the alditol acetate of glucose moiety composing the main chain of the glucan as well as 2,3,4,6-tetra- $O$-methyl-Dglucose. The fact also made it clear that the $4 \mathrm{~N}$ $\mathrm{NaOH}$-soluble glucan was a linear $\beta$-1,4glucan.

The degree of polymerization of the glucan could be estimated by determining the ratio of the total glucose residues to the non-reducing glucose residues. The ratio of 2,3,4,6-tetra- $O$ methyl-D-glucose to 2,3,6-tri- $O$-methyl-Dglucose was calculated to be 17.7 from the peak area on the chromatogram. Accordingly, the average degree of polymerization was estimated to be 18.7 .

\section{DISCUSSION}

In a disproportionation reaction of maltoand cellooligosaccharide, the specific elongation of a particular glucosidic linkage has been demonstrated on the basis of the chemical structure of a higher molecular weight glucan synthesized by the reaction. ${ }^{2,4)}$ The hydrolysates of an iodine staining glucan, which was produced by D-enzyme from maltotetraose, with salivary $\alpha$-amylase were shown to consist of only glucose, maltose, and maltotriose. $^{2)}$ Also, the chemical structure of a water-insoluble glucan (higher cellodextrin), the product of $\beta$-transglucosylase of Sclerotinia libertiana, clearly indicated the specificity of $\beta$-1,4-glucosidic linkage elongation by the enzyme. ${ }^{4)}$

$\beta$-Transglycosylase of Trichoderma longibrachiatum apparently synthesized a waterinsoluble glucan using $1 \%$ cellopentaose as the substrate (see Fig. 1). The glucan was fractionated according to the solubility in $\mathrm{NaOH}$, and the $4 \mathrm{~N} \mathrm{NaOH}$-soluble glucan was shown to be a linear $\beta$-1,4-glucan having an average degree of polymerization of 19 . As shown in Fig. 3, enzymatic hydrolysis of the waterinsoluble glucan also indicated the presence of two kinds of glucans different in the rate of hydrolysis by cellulase. As was expected from the rate of hydrolysis of the higher cellodextrin ( $\overline{\mathrm{DP}} 14)$, the $4 \mathrm{~N} \mathrm{NaOH}$-soluble glucan should rapidly hydrolyzed by cellulase. In the 
present study, the structure of the $4 \mathrm{~N} \mathrm{NaOH}$ insoluble glucan was not precisely investigated. The glucan could not be methylated by the Hakomori method using DMSO as the solvent, and the amount obtained as a dried preparation was too small to be analyzed by any other method. The water-insoluble glucan itself was completely solubilized by cellulase to give glucose, cellobiose, and cellotriose. Probably the $4 \mathrm{~N} \mathrm{NaOH}$-insoluble glucan was a linear $\beta$-1,4-glucan of high molecular weight, and was rather resistant to the cellulase action because of its size.

Several glucosyltransferases have been known to synthesize cellulose using nucleotide sugars such as GDPglucose (EC 2.4.1.29) and UDPglucose (EC 2.4.1.12) as a glucosyl donor. ${ }^{10 \sim 14)}$ Glaser reported that a cell-free preparation of Acetobacter xylinum synthesized cellulose using a mixed cellodextrin fraction as a glucosyl acceptor, where the short chain cellodextrin was suggested to be provided by a transglucosidation mediated by other enzymes of the bacterium. ${ }^{13)}$ The mechanism of cellulose synthesis has been mainly investigated for higher plants and bacteria but not for fungi. Except for the fungi having chitin or chitosan as a main polysaccharide component of the hyphal wall, relatively few fungi have cellulosic walls; Phytophthora has those the presence of which has been established through X-ray analysis and enzymatic hydrolysis tests with cellulase. ${ }^{15,16)}$ However, the polysaccharide composition of Trichoderma, a typical cellulolytic fungus, has not been well understood, while recent analysis revealed the presence of cellobiose in the acetolysates of the hyphal wall of Trichoderma longibrachiatum, suggesting the presence of cellulose in the fraction (T. Tanaka and S. Oi, unpublished data). A glucosyltransferase such as cellulose synthase of Acetobacter xylinum seems to be produced by Trichoderma longibrachiatum. In this sense, it is interesting that the fungus produced $\beta$-transglycosylase providing a $\beta$-1,4-glucan molecule, which would serve as a glucosyl acceptor in the whole synthesis of cellulose fiber by a cellu- lose synthase, as shown in cellulose synthesis by Acetobacter xylinum.

The $\beta$-transglycosylase seems to have an ability to synthesize a high molecular weight linear $\beta$-1,4-glucan (cellulose) by itself, although further analyses are needed to confirm the fact. It is reasonable that few of the lower $\beta$-1,4-glucan molecules ( $4 \mathrm{~N} \mathrm{NaOH}$-soluble glucan) once accumulated in the reaction mixture specifically accept glycosyl moieties, probably by a single chain mechanism, because the ratio of the $4 \mathrm{~N} \mathrm{NaOH}$-insoluble glucan to the total water-insoluble glucan was so low (about $5 \%$ ) with respect to the recovery yield. When the ratio is calculated on a molelcular basis, the value is much lower than that obtained above. Therefore, the $\beta$-transglycosylase should not be regarded as a cellulose synthase, but rather be regarded as a specific disproportionating enzyme with respect to the capacity and specificity of $\beta$-1,4-glucosidic linkage elongation.

\section{REFERENCES}

1) J. Monod and A. Torriani, Ann. Inst. Pasteur, 78, 65 (1950).

2) S. Peat, W. J. Whelan and W. R. Rees, Nature, 172, 158 (1953).

3) S. Peat, W. J. Whelan and W. R. Rees, J. Chem. Soc., 44 (1956).

4) T. Tanaka, R. Yamamoto and S. Oi, Agric. Biol. Chem., 47, 2731 (1983).

5) T. Tanaka, R. Yamamoto, S. Oi and D. J. Nevins, Carbohydr. Res., 106, 131 (1982).

6) T. Tanaka and S. Oi, J. Biochem., 95, 847 (1984).

7) N. Nelson, J. Biol. Chem., 153, 375 (1944).

8) S. Hakomori, J. Biochem., 55, 205 (1964).

9) T. Tanaka, S. Oi and T. Yamamoto, J. Biochem., 87, 297 (1980).

10) J. C. Chambers and A. D. Elbein, Arch. Biochem. Biophys., 138, 620 (1970).

11) H. M. Flowers, K. K. Batra, J. Kemp and W. Z. Hassid, J. Biol. Chem., 244, 4969 (1969).

12) L. Ordin and M. A. Hall, Plant Physiol., 42, 205 (1967).

13) L. Glaser, J. Biol. Chem., 232, 627 (1958).

14) J. L. Potter and R. A. Weisman, Method Enzymol., 28, 581 (1972).

15) M. Novaes-Ledieu, A. Jimenez-Martinez and J. R. Villanueva, J. Gen. Microbiol., 47, 237 (1967).

16) S. Bartnicki-Garcia, J. Gen. Microbiol., 42, 57 (1966). 